\title{
Research on Automatic Inspection Methods of Flight Quality of Digital Aerial Photography Results
}

\author{
Yanwei Zeng ${ }^{1}$, Yong Liang ${ }^{2, *}$, Wencong Jiang ${ }^{2}$, and Xiaojun Wang ${ }^{2}$ \\ ${ }^{1}$ Quality Supervision and Testing Center of National Surveying and Mapping Products, \\ Chengdu, Si Chuan Province 610081, China \\ ${ }^{2}$ School of Information Science \& Engineering, Shandong Agricultural University, Tai'an, \\ Shandong 271018, P.R. China \\ yongl@sdau.edu.cn
}

\begin{abstract}
Aerial photogrammetry is one of the main methods obtaining geospatial information. After entering the 21 st century, aerial photogrammetry technology has fully entered the digital age, and the quality of digital aerial photography results will directly affect the quality and accuracy of results of surveying and mapping. Therefore, it is necessary to inspect the quality of digital aerial photography results. In the process of digital aerial photography, flight quality directly affects the quality of the results. It is of great importance to make its flight quality inspection. Based on the analysis of flight quality index of the results of digital aerial photography and domestic and international current situation of quality inspection technology of aerial photography results, the author has researched and has posed inspection index and automatic inspection methods of flight quality of the results of digital aerial photography; they can be applied to check index, such as longitudinal overlapping degree, lateral overlapping degree, rotation angle, and the curvature of airline of images, to realize automatic quality inspection of flight quality of the results of digital aerial photography.
\end{abstract}

Keywords: Digital aerial photography, Flight quality index, Flight quality, Quality inspection, Automatic inspection.

\section{Introduction}

Digital aerial photography results are the important data sources of basic surveying and mapping, which quality will directly affect the quality of results of follow-up surveying and mapping. Therefore, it is necessary steps to make the comprehensive quality inspection to guarantee the quality of data, and it's of important application value and meaning [1]. In the process of digital aerial photography, flight quality directly affects the quality of the results, and it's important to check flight quality. It's high efficient and practical to make automatic quality inspection of flight quality based on digital image.

* Corresponding author. 


\section{Index of Flight Quality}

In this paper, based on the national standards and regulations(in table 1), the author studied and put forward quality inspection index system of flight quality of the box type digital aerial photography results(in table 2 ).

The index of flight quality includes longitudinal overlapping degree, lateral overlapping degree, inclination angle of picture, rotation angle of picture, the curvature of airline, measurement area coverage guarantee, division area coverage guarantee, the difference between the biggest navigation height and the smallest navigation height and the difference between the actual navigation height and the design navigation height and so on [2] [3].

Table 1. National standards and regulations

\begin{tabular}{|c|c|}
\hline \multirow{12}{*}{ 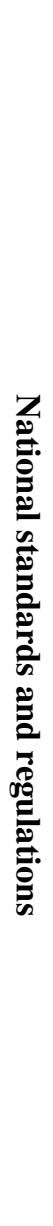 } & $\begin{array}{c}\text { GB/T 6962-2005 《Aerial Photographic specification for 1: 500、 } \\
\text { 1:1000、1:2000 Scale Topographic maps》 }\end{array}$ \\
\hline & $\begin{array}{l}\text { GB/T 15661-1955 《Aerial Photographic specification for } 1: 5000 \text { 、 } \\
1: 10000 、 1: 25000 、 1: 50000 、 1: 100000 \text { Scale Topographic maps》 }\end{array}$ \\
\hline & $\begin{array}{c}\text { GB/T 19294-2003《 } \begin{array}{c}\text { (Design specification of Aerial Photography } \\
\text { Technology } 》\end{array}\end{array}$ \\
\hline & $\begin{array}{c}\text { MH/T 1006-1996 《Inspection specification of Aerial Photography } \\
\text { Instruments》 }\end{array}$ \\
\hline & $\begin{array}{c}\text { 《Provisions of GPS Supplemental Aerial Photography Technology》 } \\
\text { ( Trying) }\end{array}$ \\
\hline & $\begin{array}{c}\text { GB/T 24356-2009 《Quality Inspection and Acceptance of Surveying } \\
\text { and Mapping Results》 }\end{array}$ \\
\hline & $\begin{array}{c}\text { 《Topographic Map Based on The Scale of 1:10000、1: } 50000 \\
\text { IMU/DGPS Supplemental Aerial Photography Technology Provisions 》 } \\
\text { ( Trying) }\end{array}$ \\
\hline & $\begin{array}{c}\text { 《Implementation Detailed Rules of Inspection and Acceptance and } \\
\text { Quality Evaluation of The National Basic Aerial Photography Results》》 } \\
\text { (Trial Draft) }\end{array}$ \\
\hline & $\begin{array}{c}\text { 《Supplement Technology Regulations of The National Basic Aerial } \\
\text { Photography } 》\end{array}$ \\
\hline & $\begin{array}{l}\text { 《Implementation Detailed Rules of Inspection and Acceptance and } \\
\text { Quality Evaluation of The National Basic Aerial Photography Results》 } \\
\text { (Submissions) }\end{array}$ \\
\hline & $\begin{array}{c}\text { 《The Format and Note of Material of The National Basic Aerial } \\
\text { Photography Results》 }\end{array}$ \\
\hline & $\begin{array}{c}\text { 《Data Arrangement and Explains of Digital Aerial Photography } \\
\text { Results》 (Trying) }\end{array}$ \\
\hline
\end{tabular}


Table 2. Flight quality index system of digital aerial photography results [4] [5]

\begin{tabular}{|c|c|c|}
\hline $\begin{array}{c}\text { Index of the second } \\
\text { class }\end{array}$ & Description of function & Accuracy \\
\hline $\begin{array}{c}\text { longitudinal } \\
\text { overlapping degree }\end{array}$ & $\begin{array}{l}\text { Calculate the overlapping degree } \\
\text { on the direction of airline between } \\
\text { two photos according to the image } \\
\text { matching method }\end{array}$ & $\begin{array}{c}\text { General is for } \\
60 \%-65 \% \text {, and } \\
\text { individuals are not } \\
\text { more than } 75 \% \text { and } \\
\text { not less than } 56 \%\end{array}$ \\
\hline $\begin{array}{c}\text { lateral overlapping } \\
\text { degree }\end{array}$ & $\begin{array}{l}\text { Calculate lateral overlapping } \\
\text { degree on the direction of airline } \\
\text { between two adjacent airline } \\
\text { photos according to the image }\end{array}$ & $30 \%-35 \%$ \\
\hline $\begin{array}{c}\text { inclination angle of } \\
\text { photos }\end{array}$ & $\begin{array}{l}\text { The angle between the main beam } \\
\text { axis of aerial photography machine } \\
\text { and the plumb line }\end{array}$ & $\begin{array}{c}\text { Not more than } 3 \\
\text { degrees }\end{array}$ \\
\hline $\begin{array}{c}\text { rotation angle of } \\
\text { photos }\end{array}$ & $\begin{array}{l}\text { Get maximum according to } \\
\text { calculating the angle of the } \\
\text { attachment line between the photo } \\
\text { lord point and box standards of two } \\
\text { photos }\end{array}$ & $\begin{array}{c}\text { Not more than } 12 \\
\text { degrees }\end{array}$ \\
\hline $\begin{array}{l}\text { the curvature of } \\
\text { airline }\end{array}$ & $\begin{array}{l}\text { Calculate the line length of the } \\
\text { photo lord point at ends of } \\
\text { airline, then Calculate the distance } \\
\text { from the photo lord point that } \\
\text { deviates farthest from the line to } \\
\text { the line, finally get the ratio } \\
\text { between the distance and the line } \\
\text { length }\end{array}$ & $\begin{array}{c}\text { Not more than } 3 \\
\text { degrees }\end{array}$ \\
\hline $\begin{array}{l}\text { measurement area } \\
\text { coverage guarantee }\end{array}$ & $\begin{array}{l}\text { Check the aerial photography } \\
\text { results containing the range of } \\
\text { design measurement area or not, } \\
\text { and judge whether to exist airline } \\
\text { gap or not }\end{array}$ & $\begin{array}{l}\text { lateral coverage } \\
\text { beyond the } \\
\text { measurement area } \\
\text { border is not less } \\
\text { than } 50 \% \text { of photos } \\
\text { and at least } 30 \% \\
\text { lateral coverage }\end{array}$ \\
\hline $\begin{array}{c}\text { division area } \\
\text { coverage guarantee }\end{array}$ & $\begin{array}{l}\text { Check the aerial photography } \\
\text { results containing the range of } \\
\text { design division area or not, and } \\
\text { judge whether to exist gap or not }\end{array}$ & $\begin{array}{c}\text { beyond the } \\
\text { division area border } \\
\text { is not less than } 30 \% \\
\text { of photos and at } \\
\text { least } 15 \%\end{array}$ \\
\hline
\end{tabular}


Table 2. (continued)

\begin{tabular}{|c|c|c|}
\hline $\begin{array}{c}\text { the difference } \\
\text { between the biggest } \\
\text { navigation height and } \\
\text { the smallest } \\
\text { navigation height }\end{array}$ & $\begin{array}{l}\text { Calculate the difference between } \\
\text { the biggest navigation height and } \\
\text { the smallest navigation height in } \\
\text { the scope of navigation tape and } \\
\text { calculate the difference between } \\
\text { the biggest navigation height and } \\
\text { the smallest navigation height in } \\
\text { division area }\end{array}$ & Not more than $50 \mathrm{~m}$ \\
\hline $\begin{array}{l}\text { the difference } \\
\text { between the actual } \\
\text { navigation height and } \\
\text { the design navigation } \\
\text { height }\end{array}$ & $\begin{array}{l}\text { Calculate the difference between } \\
\text { the actual navigation height and the } \\
\text { design navigation height on airline } \\
\text { and calculate the difference } \\
\text { between the actual navigation } \\
\text { height and the design navigation } \\
\text { height of all photos in division area }\end{array}$ & $\begin{array}{l}\text { Not more than } 5 \% \\
\text { of the design } \\
\text { navigation height }\end{array}$ \\
\hline
\end{tabular}

\section{$3 \quad$ Pretreatment}

Make pretreatment for the purpose of Building the image pyramids and the image matching. Before the flight quality inspection, we should make the matching of adjacent photos on airline and lateral overlapping photos among airlines to make sure relative position and judge overlapping degree and the rotation angle [6].

Because the original image is bigger, this paper uses the method of pyramid matching from level to level. Firstly, establish multistage thumbnail images for all images according to a certain proportion. Make feature point extracting and matching operation in the smallest level images to make sure the relative position of photos.

\subsection{Steps of Image Matching}

\subsubsection{Search for Homologous Image Points}

Use SIFT operator to search for homologous image points in thumbnail images. SIFT algorithm firstly put forward by D. G. Lowe in 1999, and is Summarized and perfected in 2004. Now SIFT feature matching algorithm is hot and difficult in feature point matching research field at home and abroad. The algorithm use feature point to extract feature descriptor, and looking for matching optimum point among descriptors and its matching ability is strong.

In quality inspection data of digital aerial photography results, there may be some aviation images which pitch, inclination and rotation angle is big and navigation height is not stable. SIFT feature keeps invariant for rotation, scale zoom and brightness variations and keeps certain stability for perspective variations, affine transformation and noise, and is suitable for image matching for quality inspection of aviation images. Figure 1 is the results scheme using SIFT operator to search for homologous image points. The top half of the picture is the left image, the bottom half is the right image and Purple lines links homologous image points. 


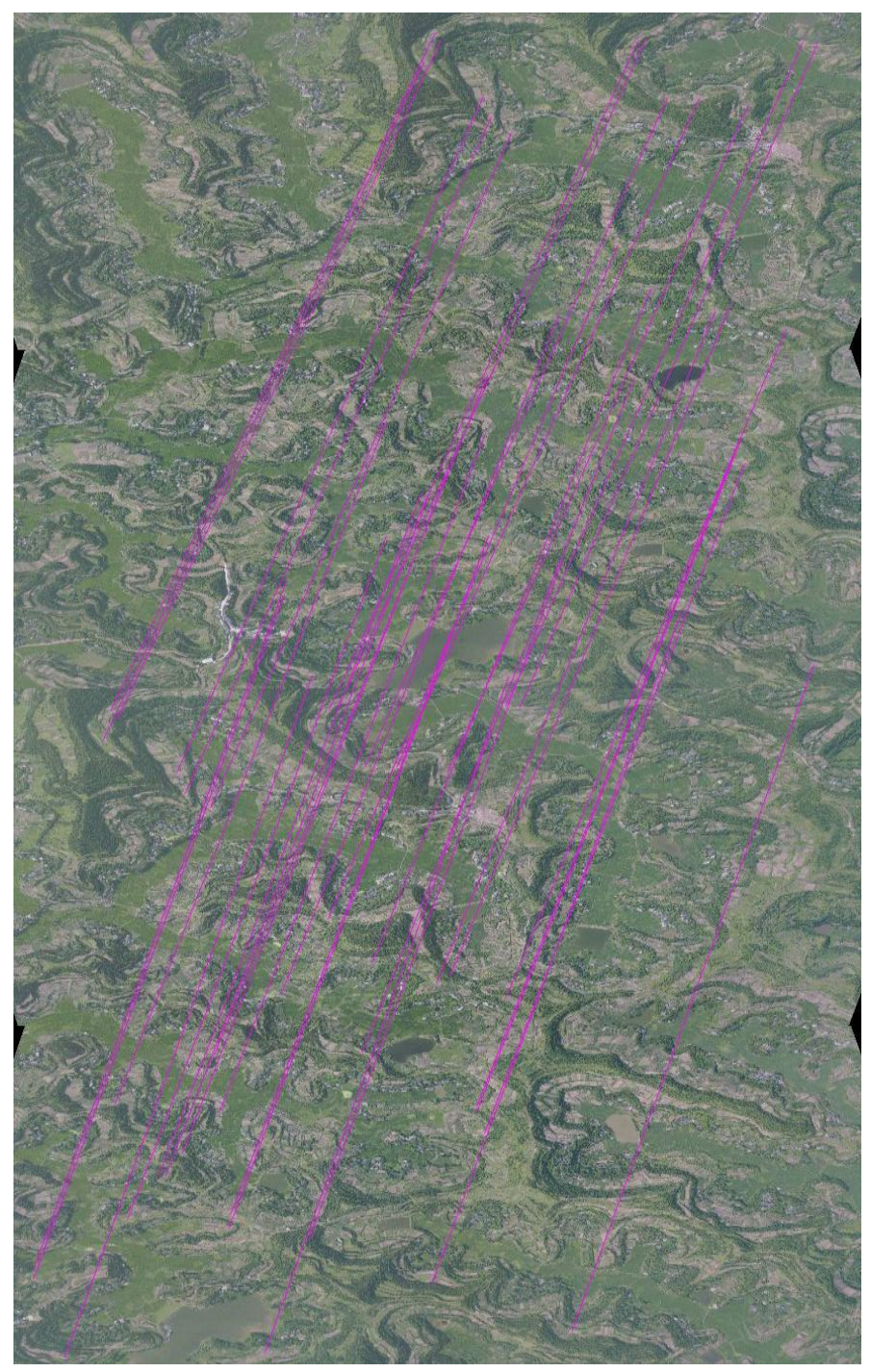

Fig. 1. Search for homologous image points in adjacent images using SIFT operator

\subsubsection{Make Sure of Relative Position between Photos}

After Searching for enough homologous image points using SIFT operator, we should use quadratic polynomial model and least square method to make relative position relationship of two images, and put the coefficient of quadratic polynomial into database as initial value to use bigger accuracy matching. In this process, it can get the right result using Constraint of deformation and rotation to eliminate the mismatching homologous points. 


$$
\begin{aligned}
& X_{I}=\sum_{i=1}^{2} \sum_{j=1}^{2} A_{i j} X_{r}{ }^{i} Y_{r}{ }^{j} \\
& Y_{I}=\sum_{i=1}^{2} \sum_{j=1}^{2} B_{i j} X_{r}{ }^{i} Y_{r}{ }^{j}
\end{aligned}
$$

This research combined with the relative position relationship between photos uses least square method to automatically set the threshold of feature points matching and its Result is better.

Through the experiment, when overlapping degree of the left and the right photos is right, the number of the effective homologous points is more than 50 . When there is no overlap, it also gives error. Figure 2 is the relative position scheme of a pair of photos in experimental results.

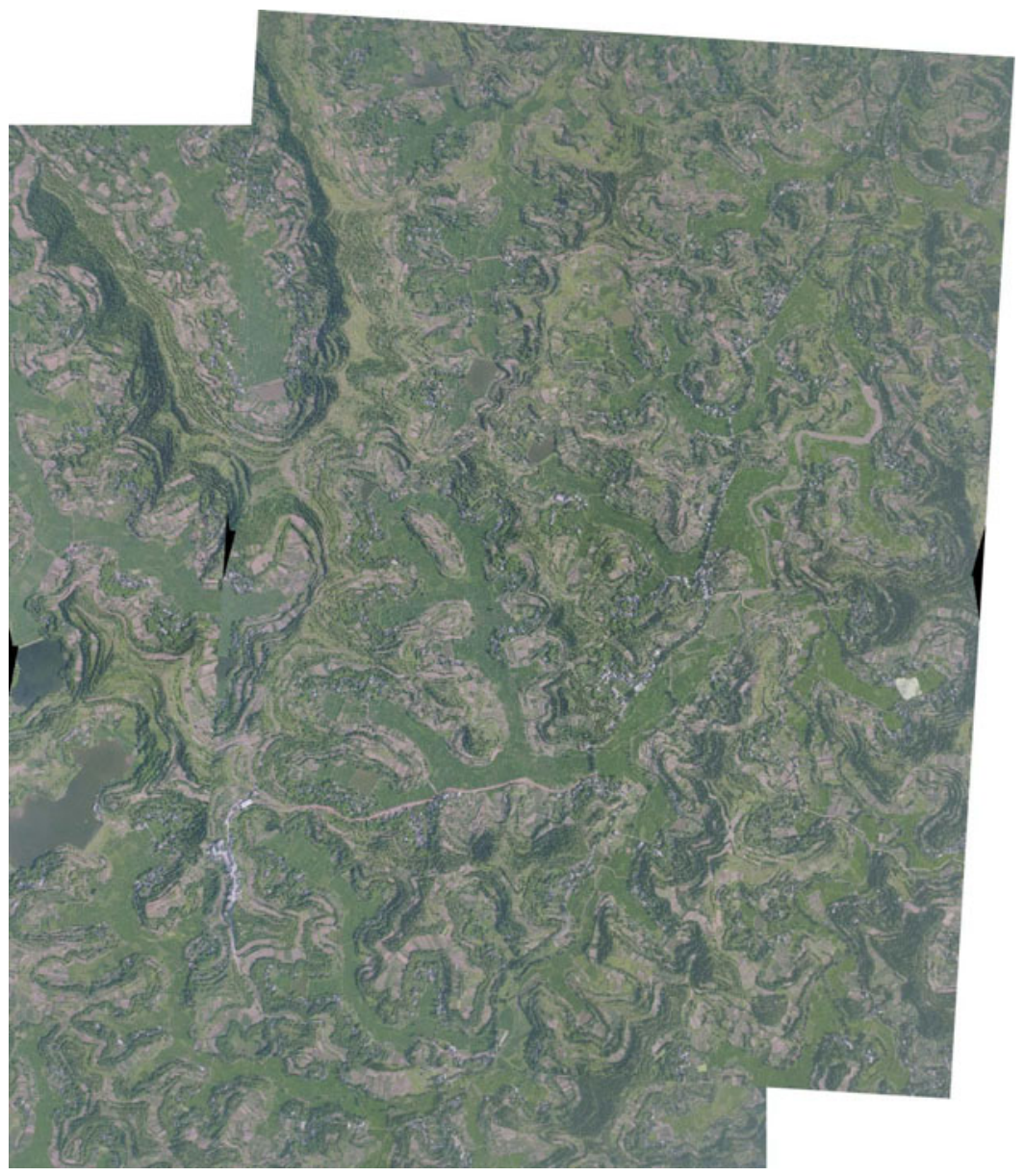

Fig. 2. Montage charts of adjacent images according to the calculation 


\section{Automatic Inspection Method of Flight Quality}

\subsection{Longitudinal Overlapping Degree}

\subsubsection{Longitudinal Overlapping Degree}

Longitudinal overlap is overlapping photography of adjacent photos on the same airline. Longitudinal overlapping degree is a ratio between side length of overlap images and long and wide of picture format and expresses as a percentage. If overlapping degree is not enough, there will be aerial photography gap and it needs to make up immediately.

\subsubsection{Calculation Method of Longitudinal Overlapping Degree}

According to the results of the pretreatment, make further image matching in the edge of image overlapping area and get the position of the left edge on the right photo. According to the requirements of the specifications we can judge whether it meets the requirements of longitudinal overlapping degree.

$$
\text { Longitudinal overlapping degree }=\frac{l_{1}}{L_{1}} \quad(\%)
$$

$l_{1}$ - Longitudinal minimum overlap width; $L_{1}$ - The length of the picture

\subsection{Lateral Overlapping Degree}

\subsubsection{Lateral Overlapping Degree}

Lateral overlap is overlapping photography between adjacent airlines, and lateral overlapping degree is a ratio between side length of lateral overlapping images and long or wide of picture format and expresses as a percentage. If overlapping degree is not enough, there will be aerial photography gap and it needs to make up immediately [7].

\subsubsection{Calculation Method of Lateral Overlapping Degree}

This method is similar to the inspection method of longitudinal overlapping degree.

$$
\text { Lateral overlapping degree }=\frac{l_{2}}{L_{2}} \quad(\%)
$$

$l_{2}$ - Lateral minimum overlap width; $L_{2}$ - The width of the picture 

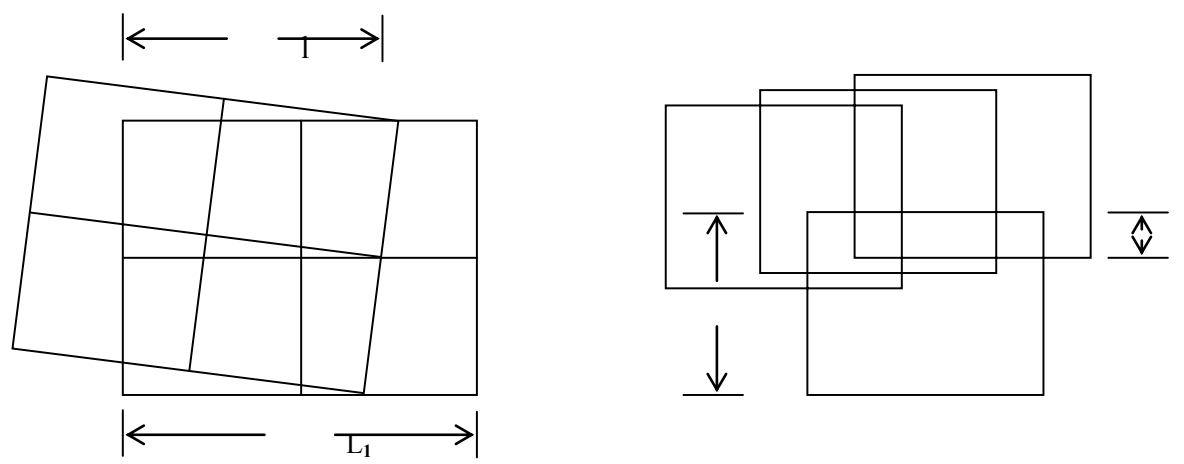

Fig. 3. Calculation schemes of longitudinal overlapping degree and lateral overlapping degree

\subsection{Angle of Inclination of the Picture}

\subsubsection{Angle of Inclination of the Picture}

Angle of inclination of the picture is the angle of main axis of the aerial camera and the plumb line.

\subsubsection{Calculation Methods of Angle of Inclination of the Picture}

View aerial apparatus records or use photogrammetry methods to check.

\subsection{Angle of Rotation of the Picture}

\subsubsection{Angle of Rotation of the Picture}

Angle of the attachment line between the photo lord point and box standards of two photos.

\subsubsection{Calculation Methods of Angle of Rotation of the Picture}

Calculate the angle according to image matching of adjacent pictures. The specific method: The existence of the rotation angle will make the whole route serrated and it affects overlapping degree. According to relative position of adjacent photos after pretreatment, we need to make further matching nearby homologous image points and get the precise location of homologous image point in the left photo relative to the right photo and homologous image point in the right photo relative to the left photo. Then we can calculate the angle according to the definition.

\subsection{Curvature of Airline}

\subsubsection{Curvature of Airline}

The maximum deviation degree from homologous image points of all photos to the line connecting homologous image point of the first photo with that of the last one[8]. 


\subsubsection{Inspection Methods}

According to the results of the image matching we can make sure of the relative position of homologous image points and calculate through the definition.

$$
\text { Curvature of airline }=\delta / L
$$

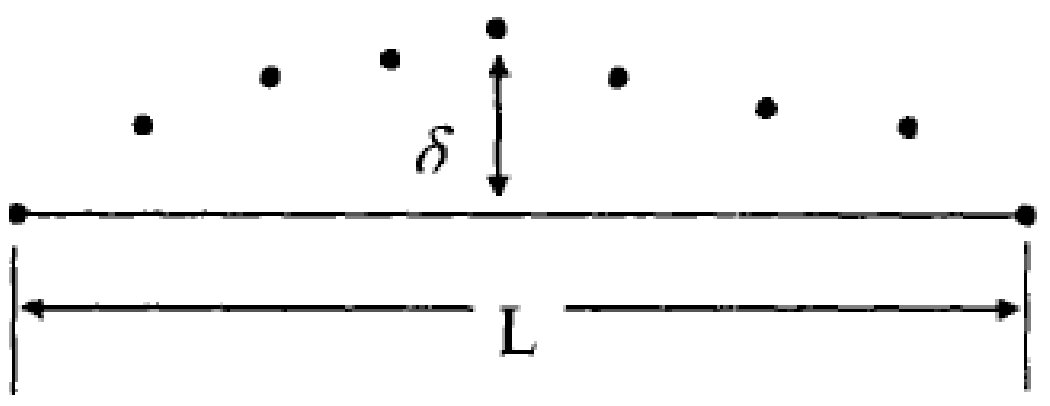

Fig. 4. Calculation scheme of curvature of airline

\subsection{Navigation Height Keeping}

\subsubsection{Navigation Height}

Navigation height is the vertical distance from remote sensing platform to datum of Photography division. We can calculate the difference of navigation height between adjacent images through the length of corresponding features in topographic map and images.

If there is GPS data, it will be easy to calculate the difference of navigation height. We only need to get all navigation height on one airline and obtain the difference between the maximum value and the minimum value. If no, we can get the difference between all photography stations and the first photo according to foreign elements got by calculating topological relationship and obtain the difference between the maximum value and the minimum value of foreign elements in each photo.

\subsubsection{Inspection Methods}

You can get parameters $Z_{i}(\mathrm{i}=1, \ldots, \mathrm{n})$ of foreign elements of homologous image points in each photo and that is navigation height. Then, you can calculate variance of all navigation height to keep navigation height.

$$
S^{2}=\frac{\sum_{i=1}^{n}\left(S_{i}-\bar{S}\right)^{2}}{n}
$$




\subsection{Difference between the Biggest Navigation Height and the Smallest Navigation Height}

Inspection methods: Get the maximum value $Z_{\max }$ and the minimum value $Z_{\min }$ through parameters $Z_{i}$ of foreign elements and the difference is as follows:

$$
\Delta Z=Z_{\max }-Z_{\min }
$$

\subsection{Difference between the Actual Navigation Height and the Design Navigation Height}

Inspection methods: Get the difference between parameters $Z_{i}$ of foreign elements in images of all measurement areas and Design Navigation Height $Z$.

$$
\Delta Z=Z_{i}-Z
$$

\subsection{Coverage Guarantee of Measurement Area}

\subsubsection{Coverage Guarantee of Measurement Area}

Airlines completely cover the whole measurement area and control design on aerial photography images is checked with homologous features nearby control line marked on topographic map [9].

\subsubsection{Inspection Methods}

Get coordinates of image center on peripheral airlines to calculate the range of coverage $\mathrm{S}^{\mathrm{A}}$, and compare with the range of design measurement area and specific steps are as follows:

(1) Draw closed polygon $\mathrm{S}$ according to boundary peripheral series coordinates $\left(\mathrm{x}^{i}, \mathrm{y}^{i}\right), \mathrm{i}=1, \cdots \mathrm{n}$, given by the map of design measurement area;

(2) Draw closed polygon $\mathrm{S}^{\mathrm{A}}$ by getting coordinates of image center on peripheral airlines $\left(\mathrm{x}^{i}, \mathrm{y}^{i}\right), \mathrm{i}=1, \cdots \mathrm{n}$;

(3) Automatically judge $\mathrm{S}^{\mathrm{A}}$ whether contains $\mathrm{S}$ or not, or judge through the human-computer interaction drawing polygon $\mathrm{S}^{\mathrm{A}}$ and $\mathrm{S}$ in different color lines.

\subsubsection{Input Data Requirements}

Coordinate system of design measurement area map is the same to that of aerial photography photos. And input data includes design map of measurement area, aerial photography photos and foreign elements. 


\subsubsection{Realization Methods}

In data preparation, we should provide the dialog box that needs to be input boundary dots and coordinates, and set the type of input data. According to the input data point coordinates, it can generate closed polygon and it's the range of design measurement area. Generate closed polygon through coordinates of image center on peripheral airlines.

\subsubsection{Airline Boundary}

If aviation coverage is one baseline beyond measurement area boundary, coordinates of image center need to be one baseline beyond boundary.

\subsubsection{Realization Methods}

It's shown by designing map polygon in measurement area and polygon connecting images center on peripheral airlines.

\subsection{Coverage Guarantee of Division Area}

Control design on aerial photography images is checked with homologous features nearby partition line marked on topographic map, and the specific method is the same to inspection of measurement area coverage guarantee [10].

\section{Conclusions}

In this paper, based on research and analysis of technology situations of quality inspection for aerial photography results, the author studies and puts forward results inspection index and method of flight quality of box type digital aerial photography and Applies to check the index such as longitudinal overlapping degree, lateral overlapping degree, inclination angle of picture, rotation angle of picture, the curvature of airline and so on.

\section{References}

[1] Yu, C., Zeng, Y.: Design on Automatic Quality Inspection System of Digital Aerial Photography Results. Information and Engineering of Surveying and Mappin 36(1), 8-10 (2011)

[2] GB/T 6962-2005:Aerial Photographic specification for 1: 500、1:1000、1:2000 Scale Topographic maps

[3] GB/T 15661-1955:Aerial Photographic specification for 1: 5000、1:10000、1:25000、 1:50000、1:100000 Scale Topographic maps

[4] Implementation Detailed Rules of Inspection and Acceptance and Quality Evaluation of the National Basic Aerial Photography Results. Bureau of National Surveying and Mapping (2001)

[5] Data Arrangement and Explains of Digital Aerial Photography Results. Bureau of National Surveying and Mapping (2007)

[6] Yuan, J.: Information Management System of Aerial Photography. Information Engineering University of Zhengzhou (2002) 
[7] Wu, S.: Design and Implementation on Digital Acceptance System of Aerial Photography Flight Quality. Information Engineering University of Zhengzhou (2005)

[8] Yuan, J., Xu, B.: Inspection Technology of Flight Quality Based on Digital images and GPS data. Journal of the PLA Surveying and Mapping Institute 22(1), 22-26 (2011)

[9] Zhang, Z., Zhang, J.: Digital Photogrammetry Science. Technology of Surveying and Mapping of Wuhan University (1996)

[10] Yuan, G., Huang, J.: Quality Control and Inspection of Digital Aerial images. Surveying and Mapping society of Jiangsu Province (2003) 